\title{
Inter-relationships between inflammatory mediators released from colonic mucosa in ulcerative colitis and their effects on colonic secretion
}

\author{
T D Wardle, L Hall, L A Turnberg
}

\begin{abstract}
Metabolites of arachidonic acid have been implicated in the pathophysiology of ulcerative colitis - they can stimulate intestinal secretion, increase mucosal blood flow, and influence smooth muscle activity. The influence on the mucosal transport function of culture medium in which colonic mucosal biopsy specimens had been incubated was investigated using rat stripped distal colonic mucosa in vitro as the assay system. Colonic tissue from patients with colitis and from control subjects was cultured. Medium from inflamed tissue contained more prostaglandin $\mathbf{E}_{2}\left(\mathrm{PGE}_{2}\right)$ and leukotriene $\mathrm{D}_{4}\left(\mathrm{LTD}_{4}\right)$ and evoked a greater electrical (secretory) response in rat colonic mucosa than control tissue medium. In inflamed tissue, cyclo-oxygenase inhibition (indomethacin) attenuated $\mathbf{P G E}_{2}$ but increased $\mathbf{L T D}_{4}$ production; conversely lipoxygenase inhibition (ICI 207968) inhibited LTD $_{4}$ production but enhanced PGE $_{2}$ output. Each inhibitor alone enhanced the electrical response in the rat colon. Inhibition of both enzymes (indomethacin plus ICI 207968) caused a fall in both $\mathrm{PGE}_{2}(82 \%)$ and $\mathrm{LTD}_{4}$ $(89 \%)$ production and in the electrical response $(57 \%)$. Inflamed tissue treated with a phospholipase $A_{2}$ inhibitor (mepacrine) produced less $\mathrm{PGE}_{2}, \mathrm{LTD}_{4}$, and electrical responses when compared with inflamed tissue, either untreated $(91 \%, 92 \%$, and $79 \%$ respectively) or treated with cyclo-oxygenase and lipoxygenase inhibition. Incubation with bradykinin stimulated eicosanoid release and electrical response, while a bradykinin antagonist caused a modest inhibition. Analysis of these observations suggests that a combination of arachidonic acid derivatives accounts for about half the secretory response. Other products of phospholipase $\mathbf{A}_{2}$ activity are probably responsible for much of the remainder, leaving up to $20 \%$ the result of types of mediator not determined in this study.
\end{abstract}

(Gut 1993; 34: 503-508)

and the Epithelial

Membrane Research

Centre, University of

Manchester, Hope

Hospital, Salford,

Manchester

T D Wardle

L Hall

L A Turnberg

Correspondence to:

T D Wardle, Department of

Medicine, Clinical Sciences

Building, Hope Hospital,

Building, Hope Hospital,
Eccles Old Road, Salford M6

8HD.

Accepted for publication

31 August 1992

High concentrations of prostaglandins and leukotrienes have been found in stool water and colonic mucosal biopsy specimens from patients with ulcerative colitis ${ }^{1-7}$ and these have been implicated in the pathophysiology of inflammatory bowel disease. They may not only be involved in the mediation and amplification of the immune response but several have also been shown to stimulate mucosal secretion, increase mucosal blood flow, and influence smooth muscle activity, each of which may be relevant to the diarrhoea that these patients suffer. ${ }^{8-10}$

Because such a wide variety of inflammatory mediators is liberated in colitis it is difficult to ascertain which, either alone or in combination, might be responsible for the associated changes in intestinal function.

We describe studies of the influence on intestinal secretion of inflammatory mediators released into the medium in which biopsy specimens of inflamed colonic mucosa were cultured. We used rat colonic mucosa in vitro as our 'assay' system for determining secretory responses. Studies of the effect of a variety of inhibitors on these responses, and on the release of a number of mediators, have allowed us to show that a combination of prostaglandins and leukotrienes are probably responsible for over half of the secretory response, and that other products of phospholipase $A_{2}$ activity are probably responsible for much of the remainder.

\section{Methods}

\section{PATIENT DETAILS}

Thirty patients underwent colonoscopy after bowel preparation. Preparation consisted of a three day low residue diet, and one day before the examination a combination of $\mathrm{X}$ prep (purified senna extract; $1 \mathrm{ml} / \mathrm{kg}$ body weight) and $10 \%$ mannitol $(500 \mathrm{ml})$ modified according to the patient's symptoms.

Ten of the patients (four men and six women, median age 36 years) had a clinical diagnosis of irritable bowel syndrome. They all had endoscopically and histologically normal mucosa.

Twenty patients (13 men and seven women median age $39 \cdot 4$ years) with active distal proctosigmoiditis had biopsy specimens taken from inflamed mucosa. Six patients were taking mesalazine ( $400 \mathrm{mg}$ three times daily), four prednisolone (5 to $15 \mathrm{mg}$ once daily), and seven topical steroids at the time of colonoscopy. All biopsy specimens were taken with non-spiked forceps to minimise tissue trauma.

Ethical approval for these studies was given by the Salford Health Authority Ethics

\section{EXPLANT CULTURE}

A series of cultures was performed for each patient. Mucosal biopsy specimens were immediately placed in transport medium (L15, sulphate), transferred to the laboratory, washed gently three times in the L15 medium, carefully with added penicillin $G$ and streptomycin 
blotted, weighed (range 3-8 mg), and placed in a $5 \mathrm{~cm}$ culture dish containing $1 \mathrm{ml}$ of culture medium (CMRL) 1066, plus glucose $5 \mu \mathrm{g} / \mathrm{ml}$, methionine $1 \mu \mathrm{M} / \mathrm{ml}$, Tris buffer $20 \mathrm{mM}$, glutamine $3 \mu \mathrm{M} / \mathrm{ml}$, $\beta$-retinyl acetate $1 \mu \mathrm{g} / \mathrm{ml}$, penicillin $\mathrm{G} 100$ units/ml, streptomycin sulphate $100 \mu \mathrm{g} / \mathrm{ml}$, gentamicin $50 \mu \mathrm{g} / \mathrm{ml}$, and ampho-

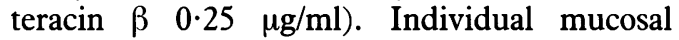
biopsy specimens were cultured with either no additives or in the presence of one of the following: indomethacin (cyclo-oxygenase inhibitor); ICI 207968 (lipoxygenase inhibitor); a combination of indomethacin and ICI 207968; mepacrine (phospholipase $\mathrm{A}_{2}$ inhibitor) (all at $10^{-5} \mathrm{M}$ ); and bradykinin, or des arg leu bradykinin (bradykinin antagonist) (both at $10^{-8} \mathrm{M}$ ). The culture dishes were placed in a humidified chamber maintained at $37^{\circ} \mathrm{C}$, supplied with a mixture of $95 \%$ oxygen $/ 5 \%$ carbon dioxide, and rotated at 10 cycles/minute. After 4 hours of culture the medium was removed and divided into three aliquots for measurement of $\mathrm{PGE}_{2}$, $\mathrm{LTD}_{4}$, and electrical responses in rat colonic mucosa.

\section{EICOSANOID MEASUREMENTS}

$\mathrm{PGE}_{2}$ and $\mathrm{LTD}_{4}$ were measured using commercially available radioimmunoassay kits ( $\mathrm{PGE}_{2}$, du Pont UK, Stevenage, Herts, UK ${ }^{11}$; $\mathrm{LTD}_{4}$, Amersham, Aylesbury, Bucks, $\mathrm{UK}^{12}$ ). Eicosanoids were extracted from the culture medium using solid phase sorbant extraction (mini columns, Amersham). The resultant sample competes with a fixed amount of radioactively labelled eicosanoid analogue (iodinated $\mathrm{PGE}_{2}$ or tritiated $\mathrm{LTD}_{4}$ ) for a limited number of binding sites. The sample $\mathrm{PGE}_{2}$ antibody complex is separated from the free antigen by polyethylene glycol precipitation and centrifugation, and then counted in a gamma counter. Separation of the leukotriene bound antibody complex was facilitated using dextran coated charcoal. After centrifugation the quantity of antibody bound radioactive ligand was measured on a beta counter.

\section{Assay performance characteristics}

Assay performance characteristics were as follows. $\mathrm{PGE}_{2}$ intra and interassay variation values were $11 \mathrm{pg} / \mathrm{ml}$ and $60 \mathrm{pg} / \mathrm{ml}$ respectively; recovery was $96 \%$ and sensitivity $0.8 \mathrm{pg} / \mathrm{ml}$. Cross reactivity (non-E prostaglandins) was $<0.4 \%$. ${ }^{11} \mathrm{LTD}_{4}$ intra and interassay variation values were $14 \mathrm{pg} / \mathrm{ml}$ and $39 \mathrm{pg} / \mathrm{ml}$ respectively; recovery was $91 \%$ and sensitivity $5 \mathrm{pg} / \mathrm{ml}$. Cross reactivity (non-sulphidopeptide leukotrienes) was $<0 \cdot 001 \%$. ${ }^{12}$

Eicosanoid concentrations were calculated by interpolation from a standard curve. All results were expressed in $\mathrm{pmol} / \mathrm{mg}$ wet tissue/ hour.

\section{RAT DISTAL COLON PREPARATION}

An in vitro technique modified from that of Ussing and Zerahn was used. ${ }^{13}$ Unfasted male Sprague-Dawley rats were killed and the distal colon was removed immediately and bathed in oxygenated buffer. Muscle layers were stripped and the two most distal pieces of mucosa were mounted as sheets, between Perspex flux chambers, with a surface area of $0.64 \mathrm{~cm}^{2}$ (VT Plastics Ltd, Warrington, UK).

The spontaneous, basal transmucosal potential difference (PD) was measured, on a high impedance digital volmeter via fine tipped electrode bridges ( $3 \mathrm{M} \mathrm{KCl}$ in 3\% agar) connected to matched calomel half cells. The short circuit current (Isc) was delivered by silver/silver chloride electrodes via $1 \mathrm{M} \mathrm{NaCl}$ in $1 \%$ agar bridges. The electrodes were connected to a voltage clamp for automatic short circuiting. The clamp was corrected for fluid resistance between the PD sensing bridges. Tissue conductance and resistance were calculated from the PD and Isc according to Ohm's law.

Each mucosal sheet was bathed on both sides with $5 \mathrm{ml}$ of isotonic buffer containing: $\mathrm{Na} 146$ $\mathrm{mM} ; \mathrm{K} 4.2 \mathrm{mM} ; \mathrm{Cl} 125.8 \mathrm{mM} ; \mathrm{HCO}_{3} 26.6 \mathrm{mM}$; $\mathrm{H}_{2} \mathrm{PO}_{4} 0.2 \mathrm{mM} ; \mathrm{HPO}_{4} \mathrm{l} .2 \mathrm{mM} ; \mathrm{Ca} 1.2 \mathrm{mM} ; \mathrm{Mg}$ $1.2 \mathrm{mM}$; and glucose $10 \mathrm{mM}$, at $\mathrm{pH} 7 \cdot 4$. The bathing media were stirred and oxygenated via a bubble lift system using $95 \% \mathrm{O}_{2} / 5 \% \mathrm{CO}_{2}$ and were maintained at a constant temperature of $37^{\circ} \mathrm{C}$

Culture medium $(100 \mu \mathrm{l})$ was added to the bathing fluid on the serosal aspect of rat colonic mucosa after electrical stability had been reached, usually after 30 minutes.

\section{SECRETORY AGONISTS}

\section{Eicosanoids}

$\mathrm{PGE}_{2}$ or $\mathrm{LTD}_{4}$, in final concentrations ranging from $10^{-10}$ to $10^{-4} \mathrm{M}$, were added to the serosal aspect of stripped rat distal colon. Changes in $\mathrm{PD}$, Isc, and resistance were recorded.

\section{Culture medium}

Culture medium $(100 \mu \mathrm{l})$ was added to the serosal aspect of stripped rat colon and electrical measurements, as described above, were recorded. The process was repeated using either medium incubated with the inhibitors to act as controls or medium from biopsy specimens cultured with the inhibitors as detailed above. The resultant rise in Isc was compared with the $\mathrm{PGE}_{2}$ and $\mathrm{LTD}_{4}$ dose response curves.

\section{CHEMICALS}

The 5 lipoxygenase inhibitor, ICI 207968, was kindly supplied by $\mathrm{Dr} R$ Dowell, Imperial Chemical Company, Alderley Edge, UK. Prostaglandin $\mathrm{E}_{2}$, bradykinin, des arg leu bradykinin, mepacrine, and indomethacin were obtained from Sigma Chemical Co, Poole, Dorset, UK. LT $\mathrm{D}_{4}$ was purchased from Cascade Biochem Ltd, University of Reading, Berks, UK.

\section{CALCULATIONS}

All values are expressed as the mean (SEM). Statistical comparisons were performed using paired and unpaired $t$ tests. ${ }^{1+}$ 


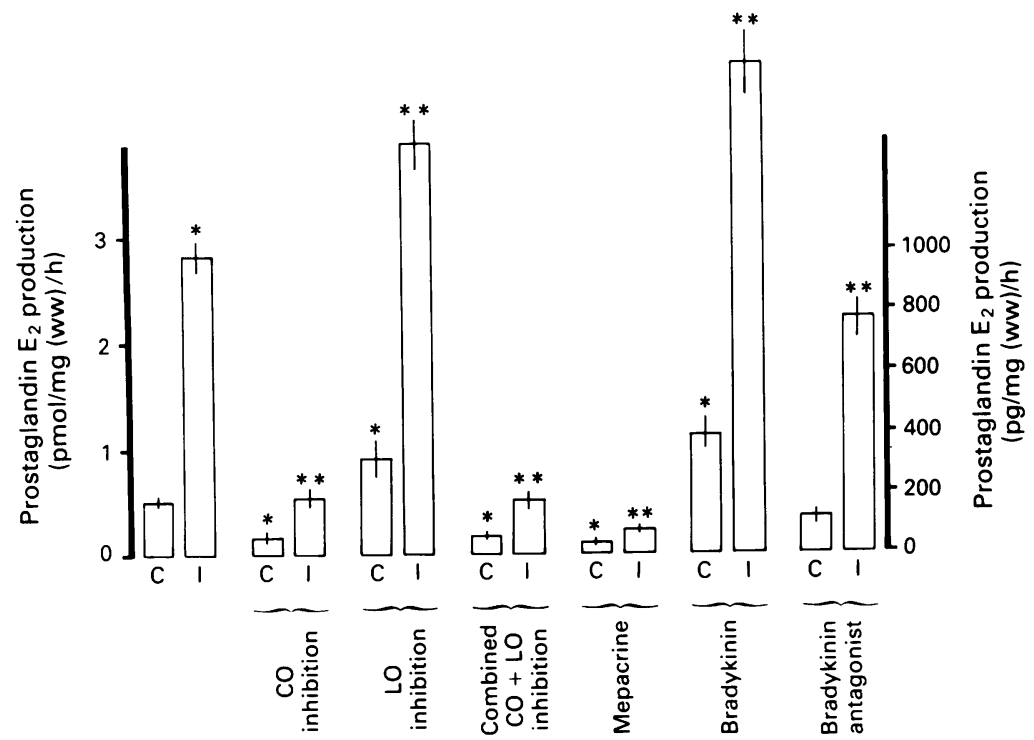

Figure 1: Prostaglandins $E_{2}$ production by cultured colonic mucosa (pmol and pg/mg wet tissue hour mean $(S E M))$. $n=10$ cultures/column. $C=$ control mucosa; I=inflamed mucosa;

$C O=$ cyclo-oxygenase inhibition (indomethacin); $L O=$ lipoxygenase inhibition (ICI 207968). $\star$ Significantly different from untreated control tissue, $p<0 \cdot 01 ; \star \star$ significantly different from untreated inflamed tissue, $p<0 \cdot 01$.

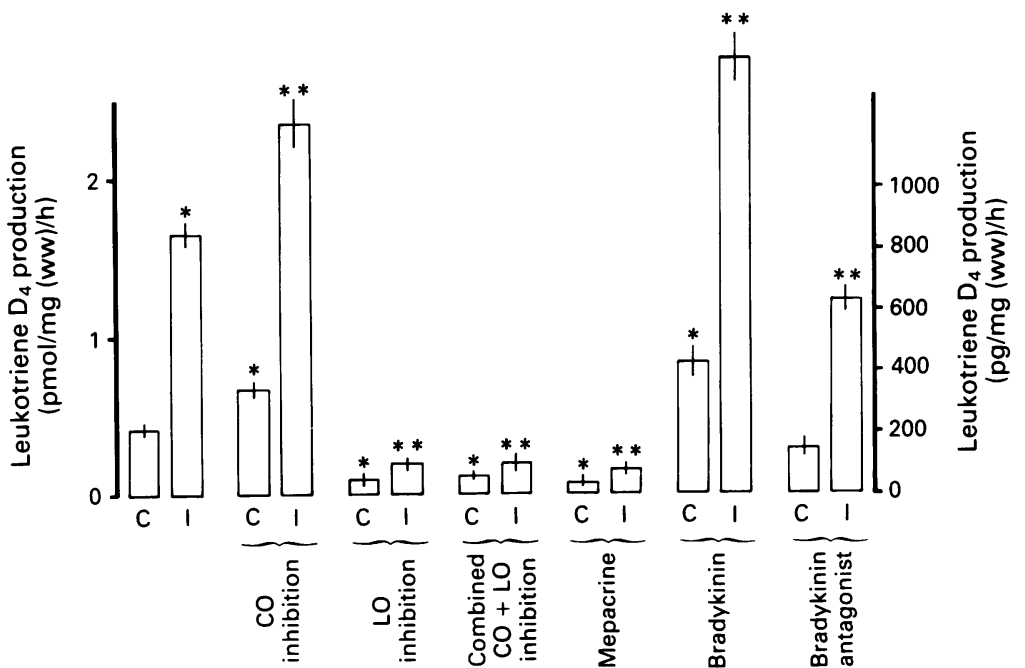

Figure 2: Leukotriene $D_{4}$ production by colonic mucosa (pmol and pg/mg wet tissue/hour mean (SEM)) $n=10$ cultures/column. $C=$ control mucosa; $I=$ inflamed mucosa; $C O=$ cyclooxygenase inhibition (indomethacin), LO=lipoxygenase inhibition (ICI 207968). $\star$ Significantly different from untreated control tissue, $p<0 \cdot 01 ; \star \star \star$ significantly different from untreated inflamed tissue, $p<0 \cdot 01$.

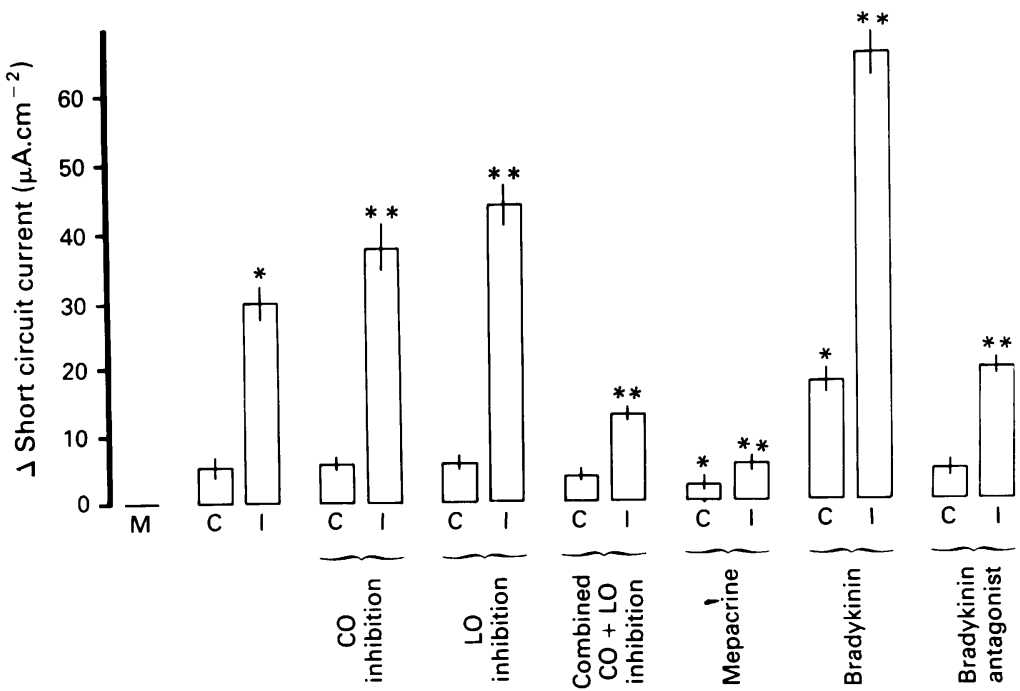

Figure 3: The effect of inflammatory mediators liberated from cultured colonic tissue on the secretory response of rat colonic mucosa; the effect of agonists and antagonists. Isc=short circuit current $\left(\mu A \mathrm{~cm}^{-2}\right.$, mean $\left.(S E M)\right) . n=4$ pieces of stripped rat distal colonic mucosa/column. current $\left(\mu A . \mathrm{cm}^{-2}\right.$, mean $\left.(S E M)\right) . n=4$ pieces of stripped rat distal colonic mucosalcolinion $M=$ medium alone, $C=$ control mucosa; $I=$ inflamed mucosa; $C O=$ cyclo-oxygenase inhibition
(indomethacin); $L O=$ lipoxygenase inhibition (ICI 207968). Significantly different from untreated control tissue, $p<0 \cdot 01 ; \star \star$ significantly different from untreated inflamed tissue, $p<0.01$.

\section{Results}

EICOSANOID MEASUREMENTS

Inflamed tissue produced significantly more $\mathrm{PGE}_{2}$ and $\mathrm{LTD}_{4}$ than control tissue $(2 \cdot 79(0 \cdot 11)$ $v 0.54(0.04) ;: 1.73(0.11) v 0.44(0.04)$ respectively, $\mathrm{p}<0.01$ ) (all values are given in $\mathrm{pmol} / \mathrm{mg}$ wet tissue weight/hour). The production rate of eicosanoids is also expressed graphically in both pmol and $\mathrm{pg} / \mathrm{mg}$ wet tissue weight/hour; for example in inflamed tissue $\mathrm{PGE}_{2}$ production is $2.79 \mathrm{pmol}$ or $1012 \mathrm{pg} / \mathrm{mg}$ wet weight/hour and $\mathrm{LTD}_{4}$ is $1.73 \mathrm{pmol}$ or $837 \mathrm{pg} / \mathrm{mg}$ wet weight/ hour. (Figs 1 and 2). Cyclo-oxygenase inhibition (indomethacin, $10^{-5} \mathrm{M}$ ) significantly reduced $\mathrm{PGE}_{2}$ production when values were compared with those in the untreated groups (inflamed $0.511(0.06)$ v $2.79(0.11)$; control $0.17(0.02) v$ $0.54(0.04) ; \mathrm{p}<0.01)$, whereas the yield of $\mathrm{LTD}_{4}$ was increased (inflamed 2.4 $(0.17) v 1.73(0.11)$ : control $0.74(0.07) v 0.44(0.04), \mathrm{p}<0.01)$.

A significant increase in $\mathrm{PGE}_{2}$ production, by all groups, followed lipoxygenase inhibition (ICI 207968, $10^{-5} \mathrm{M}$ ) (inflamed $3.9(0.22)$ v 2.79 $(0.11)$; control 0.91 (0.13) v0.54(0.04), $\mathrm{p}<0.01)$, while $\mathrm{LTD}_{4}$ generation was reduced (inflamed $0.16(0.07) v 1.73(0.11)$; control $0.1(0.01) v 0.44$ $(0.04), \mathrm{p}<0.01)$.

Combined inhibition of cyclo-oxygenase and lipoxygenase produced almost identical $\mathrm{PGE}_{2}$ results to those found after indomethacin alone (Fig 1), and $\mathrm{LTD}_{4}$ results to those found after ICI 207968 alone (Fig 2).

In inflamed tissue, phospholipase $\mathrm{A}_{2}$ inhibition (mepacrine) appreciably reduced the production of both $\mathrm{PGE}_{2}$ and $\mathrm{LTD}_{4}$ when compared with values in untreated mucosa $\left(\mathrm{PGE}_{2} 0.21(0.03) v\right.$ $2.79(0.11) ; \mathrm{LTD}_{4} 0.14(0.04) v 1.73(0.11)$ respectively; $\mathrm{p}<0.001)$. The reduction after mepacrine was also greater than that after combined cyclo-oxygenase and lipoxygenase inhibition $\left(\mathrm{PGE}_{2} 0.21(0.03) v 0.5(0.05) \mathrm{LTD}_{4}\right.$ $0.14(0.04) v 0.19(0.03)$ respectively, $\mathrm{p}<0.04)$. Mepacrine also significantly attenuated eicosanoid output by control tissue $\left(\mathrm{PGE}_{2} 0 \cdot 11\right.$ $(0.014) v 0.54(0.04) ; \mathrm{LTD}_{4} 0.1(0.08) v 0.44$ $(0.04) ; \mathrm{p}<0.01)$.

In comparison with the untreated group, bradykinin stimulated a significant increase in both $\mathrm{PGE}_{2}$ production (control $1 \cdot 1(0 \cdot 18) v 0.54$ (0.04); inflamed $4.1(0.24)$ v $2.79(0.11)$; $\mathrm{p}<0.001$ ) and $\mathrm{LTD}_{4}$ production (control $1 \cdot 1$ $(0.12)$ v $0.44(0.4)$; inflamed $4 \cdot 1(0.17) v 1 \cdot 7$ $(0 \cdot 11) ; \mathrm{p}<0.001)$

Inhibition of bradykinin resulted in a fall in $\mathrm{PGE}_{2}$ and $\mathrm{LTD}_{4}$ generation by all groups but only the reduction found in the inflamed group reached statistical significance (inflamed $\mathrm{PGE}_{2}$ $2.3(0.14) v 2.79(0.11) ; \mathrm{LTD}_{4} 1 \cdot 1(0.1)$ v 1.73 $(0.11)$ respectively; $\mathrm{p}<0.01$, control $\mathrm{PGE}_{2} 0.34$ $(0.05) v 0.54(0.04) ; \mathrm{LTD}_{4} 0.29(0.05) v 0.44$ $(0 \cdot 04)$; NS).

\section{EFFECT OF CULTURE MEDIUM ON STRIPPED RAT} DISTAL COLON

Fresh culture medium applied to the serosal half chamber did not produce any change in baseline electrical activity (Fig 3). Culture medium incubated with the inhibitors did not influence 
the basal Isc. Culture fluid from inflamed tissue evoked a significantly larger Isc increase than fluid from control mucosa (31 (2.6) v $6 \cdot 3(1 \cdot 3)$ $\left.\mu \mathrm{A} . \mathrm{cm}^{-2} ; \mathrm{p}<0.001\right)$.

\section{Cyclo-oxygenase inhibition}

Medium from control biopsy specimens cultured with or without indomethacin produced similar rises in electrical measurements. However, a significantly greater increase in Isc occurred with fluid derived from inflamed mucosal biopsy specimens treated with indomethacin, compared with the untreated group $(40(2 \cdot 5) v 31(2 \cdot 6)$ $\left.\mu \mathrm{A} . \mathrm{cm}^{-2} ; \mathrm{p}<0.01\right)$.

\section{Lipoxygenase inhibition}

Lipoxygenase inhibition with ICI 207968 did not influence the modest rise in electrical activity seen with the control biopsy medium. However, after lipoxygenase inhibition medium from inflamed tissue produced a significantly greater Isc response than that from untreated control tissues $\left(43.5(5) v 31(2 \cdot 6) \mu \mathrm{A} . \mathrm{cm}^{-2} ; \mathrm{p}<0.01\right)$.

\section{Combined lipoxygenase and cyclo-oxygenase inhibition}

There was no significant difference between the short circuit response evoked by culture medium from untreated control tissue and control biopsy specimens exposed to combined cyclo-oxygenase and lipoxygenase inhibition. Culture medium from inflamed tissue treated in the same way, however, produced a significantly lower Isc response than medium from untreated tissues $\left(13.4(2 \cdot 1) v 31(2.6) \mu \mathrm{A} . \mathrm{cm}^{-2} ; \mathrm{p}<0.005\right)$.

\section{Phospholipase $\mathrm{A}_{2}$ inhibition}

Control biopsy specimens incubated with mepacrine produced media which provoked a significantly smaller Isc response than untreated mucosal media $\left(2.5\right.$ (1) v $6.3(1.3) \mu \mathrm{A} . \mathrm{cm}^{-2}$; $\mathrm{p}<0.01)$. Medium from inflamed tissue exposed to mepacrine evoked an Isc response that was significantly lower than that from either medium from untreated tissue or from tissues exposed to

Figure 4: Prostaglandin $E_{2}$ dose response curve in stripped rat distal colon. Values are mean (SEM). Number of rat mucosal preparations under each point.

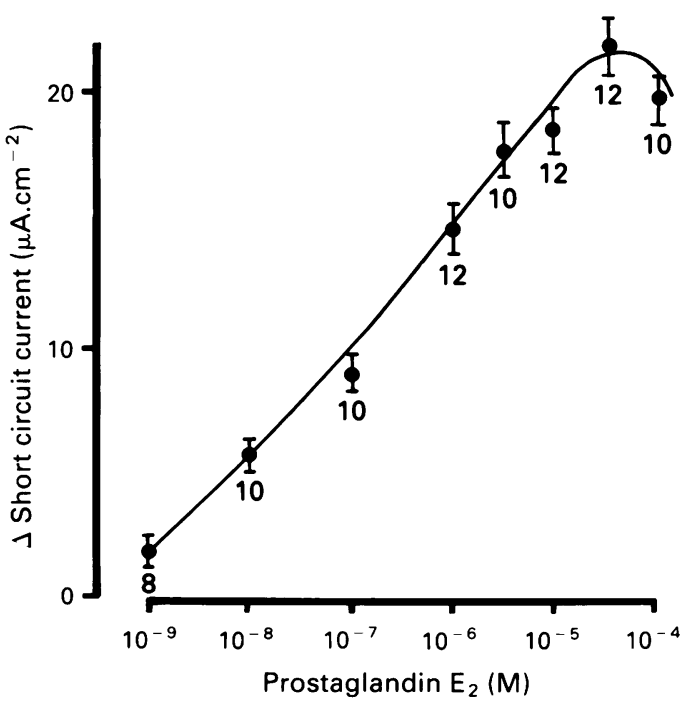

the combined effects of cyclo-oxygenase and lipoxygenase inhibition. $(6 \cdot 4(1 \cdot 1) v 31(2 \cdot 6)$ and $13.4(2 \cdot 1) \mu \mathrm{A} . \mathrm{cm}^{-2}$; respectively, $\left.\mathrm{p}<0.005\right)$.

\section{Bradykinin agonist}

The addition of bradykinin to the culture medium bathing both types of tissue produced a highly significant increase in Isc compared with values in the untreated groups (control 17.5 (2.8) $v 6.3$ (1.3): inflamed 66.1 (4.9) v $31(2 \cdot 6) \mu \mathrm{A} . \mathrm{cm}^{-2}$; $\mathrm{p}<0.001$ ).

\section{Bradykinin antagonism}

Bradykinin receptor blockade produced a fall in the Isc for both tissue types, but only in the inflamed group did the change reach statistical significance $\left(31(2 \cdot 6) v 19 \cdot 3(3 \cdot 1) \mu \mathrm{A} . \mathrm{cm}^{-2}\right.$; $\mathrm{p}<0.01)$.

\section{DOSE RESPONSE CURVES}

$P G E_{2}$

$\mathrm{PGE}_{2}$ added to the serosal, but not the mucosal, side of stripped rat distal colon caused a rapid increase in Isc, which peaked after $2 \frac{1}{2}$ to 3 minutes. The dose response curve for $\mathrm{PGE}_{2}$ gave an $\mathrm{EC}_{50}$ of $5 \times 10^{-7} \mathrm{M}$ (Fig 4). $\mathrm{PGE}_{2}$ generated a parallel but smaller increase in $\mathrm{PD}$ and a modest rise in tissue conductance.

$\mathrm{LTD}_{4}$

$\mathrm{LTD}_{4}$ added to the serosal aspect of stripped rat distal colon, evoked a rapid rise in Isc, which peaked after $2 \frac{1}{2} 2$ minutes (Fig 5). The $\mathrm{EC}_{50}$ for this response was $8 \times 10^{-7} \mathrm{M}$. The transmucosal $\mathrm{PD}$ also increased while conductance rose to a modest extent.

\section{Combined $P G E_{2}$ and $L T D_{4}$}

At the peak Isc response to $\mathrm{PGE}_{2}$ at $10^{-5} \mathrm{M}$ and $10^{-8} \mathrm{M}, \mathrm{LTD}_{4} 10^{-5} \mathrm{M}$ and $10^{-8} \mathrm{M}$ respectively were added to the serosal chamber. The combined Isc for $10^{-5} \mathrm{M}$ was $43.4 \mu \mathrm{A} . \mathrm{cm}^{2}$ and for $10^{-8} \mathrm{M}$ it was $20 \cdot 8 \mu \mathrm{A} . \mathrm{cm}^{2}$. These values were not significantly different from those expected from the dose response curves $\left(41 \cdot 5 \mu \mathrm{A} . \mathrm{cm}^{2}\right.$ :

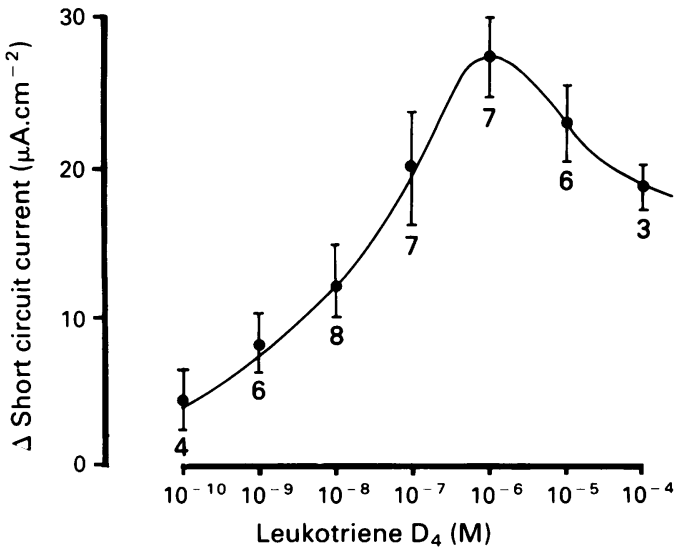

Figure 5: Leukotriene $D_{+}$dose response curve in stripped rat distal colon. Values mean (SEM). Number of rat mucosal preparations under each point. 
$18.5 \mu \mathrm{A} . \mathrm{cm}^{2}$ respectively - that is, there was no evidence of potentiation at either maximal or half maximal concentration.

\section{Discussion}

In these studies we have shown that inflamed tissue releases more eicosanoids into the culture medium than control mucosa, and that medium from any of the tissues will evoke an electrical response in stripped rat distal colon. A rise in electrical potential difference and Isc in this mucosal preparation is associated with secretion of chloride ions and we have used a rise in electrical measurements as a proxy for anion secretion.

Inflamed tissue produced significantly more $\mathrm{PGE}_{2}$ and $\mathrm{LTD}_{4}$ than control mucosa, but the difference was not as great as that shown by rectal dialysis. ${ }^{15} 16$ Although the degree of indomethacin induced cyclo-oxygenase inhibition is variable,${ }^{17}$ all groups showed significant attenuation of $\mathrm{PGE}_{2}$ production and a reciprocal, significant increase in $\mathrm{LTD}_{4}$ generation. Conversely, inhibition of lipoxygenase activity resulted in a suppression of $\mathrm{LTD}_{4}$ generation and stimulation of $\mathrm{PGE}_{2}$ synthesis. Presumably, the increased availability of arachidonate for one enzyme system when the alternative route was blocked is responsible for these reciprocal effects on $\mathrm{PGE}_{2}$ and $\mathrm{LTD}_{4}$ production.

Because $\mathrm{PGE}_{2}$ and $\mathrm{LTD}_{4}$ have each been shown to stimulate intestinal secretion ${ }^{18-21}$ it is not surprising to find that inhibiting the production of one of these did not reduce the secretory (electrical) response to medium, in which a reciprocal rise in the other had occurred. More difficult to explain is the greater Isc response to medium in which one stimulant was appreciably depressed while the other was only moderately increased. It is possible that the inhibition of the lipoxygenase or cyclo-oxygenase pathways caused the synthesis of more potent secretagogues than simply the two measured in this study. Other potential contenders for this role include prostacyclin, a more potent secretagogue than $\mathrm{PGE}_{2}{ }^{22}$ in the case of lipoxygenase inhibition, and other leukotrienes $\left(\mathrm{B}_{4}, \mathrm{C}_{4}\right)$ in the case of cyclo-oxygenase inhibition..$^{21}$

This type of analysis leads to the conclusion that there is a finely balanced production of the major metabolites of arachidonic acid and that subtle alterations in the relative activities of the enzymes concerned will cause variable responses. Blockade of a major pathway, as in this study, can thus produce unpredictable changes in functional responses. The failure of early attempts to treat ulcerative colitis with cyclooxygenase inhibitors may be explicable on this basis. ${ }^{23-27}$

Simultaneous blockade of cyclo-oxygenase and lipoxygenase pathways reduced both $\mathrm{PGE}_{2}$ and $\mathrm{LTD}_{4}$ production, as might be expected, and also attenuated the electrical response of rat colonic mucosa to this culture medium. However, the $82 \%$ reduction in $\mathrm{PGE}_{2}$ production and the $89 \%$ reduction in $\mathrm{LTD}_{4}$ production was associated with only a $57 \%$ reduction in transmucosal Isc suggesting that other factors are probably involved in provoking the electrical response. One possibility is that potentiation between the effects of low concentrations of these metabolites might occur. Such a potentiation would have to be greater at low than at high concentrations to account for this observation and we did not find evidence of potentiation between $\mathrm{PGE}_{2}$ and $\mathrm{LTD}_{4}$ in our study. Thus, this seems a less likely explanation than the simultaneous generation of other types of secretory agonists. In favour of this are the results of phospholipase $A_{2}$ inhibition with mepacrine. Here blockade of the enzyme responsible for arachidonic acid liberation caused a much greater fall in the electrical response of rat colonic mucosa (from $57 \%$ after combined lipoxygenase and cyclo-oxygenase inhibition to $79 \%$ after phospholipase $\mathrm{A}_{2}$ inhibition). $\mathrm{PGE}_{2}$ and $\mathrm{LTD}_{4}$ production were also further reduced ( $82 \%$ to $92 \%$ and $89 \%$ to $91 \%$ respectively), but these falls were much less impressive than the fall in Isc.

It is interesting to compare the electrical responses to culture media (with their measured eicosanoid concentrations) with the dose response curves for $\mathrm{PGE}_{2}$ and $\mathrm{LTD}_{4}$. It is clear that the concentrations of both eicosanoids measured in the culture media are much lower than those that might be expected to provoke the electrical responses which were observed if their effects were simply additive. The mean eicosanoid concentrations derived from culture medium from inflamed tissue were in the order of $4.45 \times 10^{-11} \mathrm{M}$ for $\mathrm{PGE}_{2}$, and $2.77 \times 10^{-11} \mathrm{M}$ for $\mathrm{LTD}_{4}$. As indicated by the dose response curves, no change in Isc would be expected with these amounts, even if these concentrations were summated. The mean rise in Isc evoked by medium from inflamed cultures was $30 \mu \mathrm{A} . \mathrm{cm}^{-2}$ which would be expected at concentrations of some $10^{-5} \mathrm{M} \mathrm{PGE}_{2}$, or $10^{-6} \mathrm{M} \mathrm{LTD}_{4}$, if these were the only mediators present. Clearly other mediators must also be involved in the electrical response, but the degree of inhibition by mepacrine (79\%) suggests that most are likely to be products of phospholipase $A_{2}$ activation.

It may be concluded from these observations that cyclo-oxygenase and lipoxygenase products account for most (57\%) of the electrical response induced by medium from cultured colonic mucosa. Only $\mathrm{PGE}_{2}$ and $\mathrm{LTD}_{4}$ were measured in these studies and since they could only be held responsible for part of the response, other cyclooxygenase and lipoxygenase products are likely to have contributed.

Moreover, other phospholipase $\mathrm{A}_{2}$ metabolites are probably responsible for a further $22 \%$ of the electrical response. It seems most likely that this is due to a non-arachidonic acid derivative, platelet activating factor being a reasonable contender for this role.

The remaining $21 \%$ of the electrical response produced by medium from cultured inflamed biopsy specimens could be caused by a variety of other mediators such as histamine, 5-hydroxytryptamine and, possibly, transmitters liberated from neural tissues.

Because much of the electrical, secretory response to culture medium could be ascribed to the release of products of phospholipase $A_{2}$ activity it was of interest to investigate the 
influence of one potentially important stimulus to phospholipase $\mathrm{A}_{2}$ activity. Inflammatory cells, in particular macrophages have receptors for bradykinin, a potent secretagogue acting almost entirely by stimulating arachidonic acid release via phospholipase $A_{2}$ activation. Its effect on intestinal mucosa, at least in the rat ileum, is indirect, its site of action being on subepithelial cells. ${ }^{28}{ }^{29}$ In our study bradykinin caused a noticeable rise in eicosanoid release from control and inflamed biopsy specimens and culture medium from these caused a greater rise in Isc in the rat colonic mucosa model. Bradykinin receptor blockade with des arg leu bradykinin caused a fall in eicosanoid output and the associated Isc response, suggesting that bradykinin may be a stimulus to endogenous phospholipase $A_{2}$ activity in biopsy specimens of normal and inflamed colonic mucosa. The fall in $\mathrm{PGE}_{2}$ and $\mathrm{LTD}_{4}$ production after bradykinin receptor blockade was, however, less than that found after direct phospholipase $\mathrm{A}_{2}$ inhibition with mepacrine or after combined lipoxygenase and cyclo-oxygenase inhibition. Reasons for this smaller effect include the possibility that receptor blockade with des arg leu bradykin was incomplete in these specimens. It is also likely that the other stimuli to phospholipase $\mathrm{A}_{2}$ activity such as interleukin $1,{ }^{30}$ interleukin 8 , and other monocyte derived growth factors, ${ }^{31}$ are liberated in these tissues.

Although we have focussed on the secretory effects of these inflammatory mediators, it is clear that they are likely to have a number of other effects that will contribute to the pathophysiology of the disease. The effects, on secretion, described here, however, provide one indicator of the tissue response in inflammatory disease.

In conclusion, we have provided evidence in favour of the view that eicosanoids are the major inflammatory mediators causing secretory responses in colonic mucosa and that their production can be significantly reduced by combined cyclo-oxygenase and lipoxygenase inhibition or by mepacrine or by a bradykinin antagonist. The maximal reduction in eicosanoid release and secretory response was achieved with mepacrine and this may warrant further clinical evaluation of its therapeutic role in inflammatory bowel disease. Care should be taken in the assessment of drugs which influence inflammatory mediator metabolic pathways since disturbance of these complex interactions and balances may produce unpredictable results.

We are grateful to Dr $\mathbf{R}$ Dowell of the Imperial Chemical Industries for donating the 5-lipoxygenase inhibitor. We are indebted to the Ileostomy Association for their financial support and interest in our work. We would also like to thank Carol McDonna for typing the manuscript.

1 Gould SR. Prostaglandins, Ulcerative colitis and sulphasalazine. Lancet 1975; ii: 988 .

2 Sharon P, Ligumsky M, Rachmilewitz D, Zor U. Role of prostaglandins in ulcerative colitis. Enhanced production during active disease and inhibition by sulphasalazine. Gastroenterology 1978; 75: 638-40.
3 Sharon P, Stenson WF. Enhanced synthesis of leukotriene $B_{4}$ by colonic mucosa in inflammatory bowel disease. Gastroenterology 1984; 86: 435-60.

4 Ligumsky M, Karmeli F, Sharon P, Zor U, Cohen F, Rachmilewitz D. Enhanced thromboxane $A_{2}$ and prostaRachmilewitz $\mathrm{D}$. Enhanced thromboxane $\mathrm{A}_{2}$ and prosta-
cyclin production by cultured rectal mucosa in ulcerative cyclin production by cultured rectal mucosa in ulcerative
colitis and its inhibition by steroids and sulfasalazine. colitis and its inhibition by stero
Gastroenterology 1981;81: 444-9.

5 Boughton-Smith NK, Hawkey CJ, Whittle BJR. Biosynthesis of lipoxygenase and cyclo-oxygenase products from ${ }^{14} \mathrm{C}$ arachidonic acid by human colonic mucosa. Gut 1983; 24: 1176-86.

6 Peskar BM, Dreyling KW, Peskar BA, May B, Goebell H. Enhanced formation of sulfidopeptide leukotrienes in ulcerative colitis and Crohn's disease: inhibition by sulfasalazine and 5-aminosalicyclic acid. Agents Action 1986; 18: 381-3.

7 Wardle TD, Turnberg LA. Co-culture of colonic mucosa - a novel technique for investigating the role of soluble mediators in inflammatory bowel disease. Gastroenterology 1990; 98: in inflam.

8 Hawkey CJ, Rampton DS. Prostaglandins and the gastrointestinal mucosa, are they important in its function, disease or treatment? Gastroenterology 1985; 89: 1162-88.

9 Rask-Madsen J. Eicosanoids and their role in the pathogenesis of diarrhoeal diseases. Clin Gastro 1986; 15: 545-66.

10 Bennett A, Eleg KG, Scholes GB. Effects of prostaglandin $E_{1}$ and $E_{2}$ on human, guinea pig and rat isolated small intestine. BrF Pharm 1968; 34: 630-8.

11 NEN Research. Instruction manual for measurement of prostaglandin $E_{2}$ in plasma and tissue samples. 1988.

12 Leukotriene $C_{4} / D_{4} / E_{4}$ assay system. Hertford: Du Pont, Amersham: Amersham International, 1988.

13 Ussing HH, Zerahn K. Active transport of sodium as a source of the electric current in short circuited isolated frog skin. Acta Physiol Scan 1951; 23: 110-27.

14 Snedecor GW, Cochran WG. Statistical methods, 7th Edition. Ames, Iowa; Iowa State University, 1980.

15 Lauritsen K, Laursen LS, Bukhave K, Rask-Madsen J. Intra luminal colonic levels of arachidonic acid metabolites in
lumitsen ulcerative colitis. Advances in Prostaglandin Thromboxane Leukotriene Research 1987; 17: 347-52.

16 Lauritsen K, Laursen LS, Bukhave K, Rask-Madsen J. In vivo profiles of eicosanoids in ulcerative colitis, Crohn's colitis and clostridium difficle colitis. Gastroenterology 1988; 95: 11-7.

17 Moore PK. Effect of drugs on arachidonic acid metabolism. In eds: Prostanoids: pharmacological, physiological and clinical eds: Prostanoids: pharmacological, physiological and clinical
relevance. Cambridge, Cambridge University Press, 1988, relevance.

18 Smith PL, Montzka DP, McCafferty GP, Wasserman MA, Fondacaro JD. Effect of sulphidopeptide leukotrienes $\mathrm{D}_{4}$ and $\mathrm{E}_{4}$ on ileal ion transport in
$\mathcal{F}$ Physiol $1988 ; 255: \mathrm{G} 175-83$.

19 Kimberg DV, Field M, Johnson J, Henderson A, Gershon E. Stimulation of intestinal mucosa adenylate cyclase by cholera enterotoxin and prostaglandin. $\mathcal{F}$ Clin Invest 1971; 50: $1218-30$

20 Field $M$, Musch MW, Steff JS. Role of prostaglandins in the regulation of intestinal electrolyte transport. Prostaglandins 1987; 21: 73-9.

21 Musch MW, Miller RJ, Field M, Siegel MI. Stimulation of colonic secretion by lipoxygenase metabolites of arachidonic acid. Science 1982; 217: 1255-6.

22 Moriarty K, Wardle T, Higgs NB, Tonge A, Warhurst G. Prostacyclin regulates secretion in mammalian colon via dual calcium and cyclic AMP dependent mechanisms comparison with PGE 2 . Gastroenterology 1990; 98: A549.

23 Gould SR, Brash AR, Conolly ME, Lennard-Jones JE. Studies of prostaglandins and sulfalazine in ulcerative colitis. Prostaglandins Med 1981; 6: 165-82

24 Gilat T, Ratan J, Rosen P, Peled Y. Prostaglandins and ulcerative colitis. Gastroenterology 1978; 76: 1083 .

25 Campieri M, Lanfranchi GA, Bazzochi G. Prostaglandins, indomethacin and ulcerative colitis. Gastroenterology 1980; 78: 193.

26 Rampton DS, Sladen GE. Prostaglandin synthesis inhibitors in ulcerative colitis: flurbiprofen compared with conventional treatment. Prostaglandins 1987; 21: 417-25.

27 Rampton DS, Sladen GE. Relapse of ulcerative proctitis during treatment with non-steroidal anti-inflammatory drugs. Postgrad Med F 1981; 57: 297-9.

28 Warhurst G, Higgs NB, Lees $M$, Tonge A, Turnberg LA. Site and mechanisms of action of kinins in rat ileal mucosa. Am $\mathcal{f}$ Physiol 1987; 252: G293-300.

29 Lawson LD, Powell DW. Bradykinin stimulated eicosanoid synthesis and secretion by rabbit ileal components. Am $\mathcal{F}$ Physiol 1987; 252: G783-90.

30 Cominelli F, Nast CC, Dinarello CA, Gentilini P, Sipser RD. Regulation of eicosanoid production in rabbit colon by interleukin 1. Gastroenterology 1989; 97: 1400-5

31 Cominelli F, Dinarello CA. Interleukin 1 in the pathogenesis of and protection from inflammatory bowel disease. Biotherapy $1989 ; 1 ; 369-75$. 